\title{
Effect of cysteamine on mucosa regeneration of intestinal trauma goats and on duodenal cell proliferation of cows in primary culture*
}

\author{
Z. Shen ${ }^{21}$, J. He and L. Cao \\ Key Laboratory of Animal Physiology and Biochemistry, \\ College of Veterinary Medicine, Nanjing Agricultural University \\ Weigang Road 1, Nanjing 210095, P.R. China
}

\begin{abstract}
Eight postoperative goats with intestinal trauma were orally supplemented with cysteamine hydrochloride (CS) in a dose of $45(\operatorname{Exp}, \mathrm{n}=4)$ or $0 \mathrm{mg} \cdot \mathrm{kg}^{-1} \mathrm{BW}$ per day (Con, $\left.\mathrm{n}=4\right)$, respectively, to investigate the effects of CS on mucosal morphology. The duodenal epithelial cells of cows $(n=3)$ were cultured to determine DNA synthesis and anti-oxidation capacity. Compared with Con the villous height in duodenum (DM) and in proximal jejunum (PJ) was enhanced significantly $(\mathrm{P}<0.05)$ in Exp, the crypt depth also increased in these two tissues $(\mathrm{P}=0.08, \mathrm{P}=0.06)$. The RNA/ DNA ratio decreased in Exp for DM $(\mathrm{P}=0.10)$ and for $\mathrm{PJ}(\mathrm{P}<0.05)$. CS also enhanced mucosal $\gamma$-glutamyl transferase activity in the $\mathrm{DM}$ or $\mathrm{PJ}(\mathrm{P}<0.05)$, and the alkaline phosphatase activity in the $\mathrm{PJ}(\mathrm{P}=0.08)$. These data indicated that $\mathrm{CS}$ induced mucosa hyperplasia rather than hypertrophy in DM and PJ. This was supported by in vitro experiment, in which CS stimulated DNA synthesis and enhanced total anti-oxidation capacity and the intracellular glutathione concentration in cultured duodenal cells of cows $(\mathrm{P}<0.05)$.
\end{abstract}

KEY WORDS: cysteamine, mucosa regeneration, anti-oxidation, postoperative goat

\section{INTRODUCTION}

Goats, equipped with permanent fistula in rumen and duodenum, are widely used as experimental models for nutritional and physiological studies. However, in postoperative animal with surgical trauma the intestinal mucosal structure and function are usually altered, leads to mucosal atrophy, increased intestinal

\footnotetext{
* Supported by Nature Science Foundation China, No. 30270972

${ }^{1}$ Corresponding author: e-mail: zmshen@njau.edu.cn
} 
permeability, bacterial translocation and infection (Fink, 1991), which partly associated with depressed immune activity (Shen and Xie, 2004).

Cysteamine (2-mercaptoethylamine) exerts multiple effects on mammalian physiology. Of its several functions, cysteamine acts as a somatostatin (SS)inhibitor, depleting SS in the brain and peripheral tissues and augmenting growth hormone (GH) concentration (Beal and Martin, 1984; McLeod et al., 1995). Cysteamine also acts as anti-oxidant in vivo (Suzy et al., 2002). Moreover, cysteamine hydrochloride attenuated the suppression of IL-2 and lymphocyte proliferation induced by surgery stress (Shen and Xie, 2004). It is accepted that GH-IGF-1 axis promoting cell proliferation in most cell types. Moreover, the antioxidation (Miller, 1999; Babu et al., 2001) is closely associated with intestinal mucosal growth. Accordingly, cysteamine could be a potential growth-promoting agent for treatment of intestinal trauma.

In this study the effects of cysteamine hydrochloride on mucosal regeneration of small intestine was investigated by using the postoperative goats, suffered from surgery trauma in intestine, as animal model. The effect of cysteamine hydrochloride on DNA synthesis and anti-oxidation were estimated by administered cysteamine to duodenal cells of cow in primary culture.

\section{MATERIAL AND METHODS}

Eight male postoperative goats $(5$-month, BW $21.4 \pm 2.6 \mathrm{~kg})$, suffered from surgery trauma in intestinal mucosa, were randomly allocated into control (Con, $\mathrm{n}=4)$ and experimental group (Exp, $\mathrm{n}=4)$. They were offered concentrate $(100$ $\mathrm{g} \cdot \mathrm{d}^{-1}$ ) and hay ad libitum. The goats in Exp group were orally supplemented with cysteamine hydrochloride compound (CS) in a dose of $45 \mathrm{mg} \cdot \mathrm{kg}^{-1} \mathrm{BW}$ per day (intestinal-lysis microcapsules, containing $30 \%$ of cysteamine, donation of Shanghai Walcom Bio-Chem Co., Ltd.) for 4 weeks.

Blood was sampled from jugular vein in both $\operatorname{Exp}(n=3)$ and $\operatorname{Con}(n=3)$ groups at the $14^{\text {th }}$ day (since the commencement of the feeding trial) to examine the PHAinduced lymphocyte transformation, ascertained by incorporation of ${ }^{3} \mathrm{H}$-thymidine $\left({ }^{3} \mathrm{H}-\mathrm{TdR}\right.$, Shanghai Atomic Energy Institute, Shanghai, China) into DNA (Yang et al., 2006). The lymphocyte proliferation rate was expressed as stimulating index (SI), SI $=\mathrm{cpm}(\mathrm{PHA}+) / \mathrm{cpm}(\mathrm{PHA}-)$.

At the slaughter, the fresh tissues of duodenum, jejunum and ileum were sampled to determine the villous size and crypt depth (Zitnan et al., 2003) The mucosa of these tissues was collected for analysis of mucosal composition of protein, nucleic acid, the activities of alkaline phosphatase (AP) and $\gamma$-glutamyl transferase $(\gamma-\mathrm{GT})$ by using commercial kits (Nanjing Jiancheng Bioengineering Institute, Nanjing, China). 
The mid-duodenum were collected from cows and trypsinized to get individual cells. These individual epithelial cells were incubated in the medium of MEM (GIBCO) added with $8 \%$ foetal calf serum, $2 \mathrm{mmol} / 1 \mathrm{~L}$-glutamine and antibiotics. Cysteamine was administered at dose of $10 \mu \mathrm{g} / \mathrm{ml}$ (Exp) or $0 \mu \mathrm{g} / \mathrm{ml}$ (Con) for $20 \mathrm{~h}$ followed by ${ }^{3} \mathrm{H}-\mathrm{TdR}(1 \mu \mathrm{Ci} / \mathrm{ml})$ treatment for another $8 \mathrm{~h}$. The cells were collected to determine the DNA synthesis in S phase (characterized by ${ }^{3} \mathrm{H}-\mathrm{TdR}$ incorporation into DNA), the total anti-oxidation capacity (T-AOC) and the intracellular glutathione concentration (GSH) was determined by using commercial kits (Nanjing Jiancheng Bioengineering Institute, Nanjing, China).

Data were expressed as mean \pm SEM. The significance was determined by Student's t-test. $\mathrm{P}<0.05$ was considered to be significant. The program of SPSS for windows (vision 10.0.0, SPSS Inc., Chicago, IL, USA) was used for statistical calculation.

\section{RESULTS}

The oral cysteamine hydrochloride administration altered the appearance of mucosa in duodenum and proximal jejunum (Table 1). The villous height in Exp groups of duodenum $(\mathrm{P}<0.05)$ and proximal jejunum $(\mathrm{P}<0.05)$ is greater than that in Con group. This was accompanied by enhanced crypt depth in mucosa of duodenum $(\mathrm{P}=0.08)$ and proximal jejunum $(\mathrm{P}=0.06)$.

Table 1. Influence of orally administrated cysteamine hydrochloride on small intestinal mucosa morphology of postoperative goats $(n=4)$

\begin{tabular}{lcccc}
\hline & Duodenum & $\begin{array}{l}\text { Proximal } \\
\text { jejunum }\end{array}$ & $\begin{array}{c}\text { Distal } \\
\text { jejunum }\end{array}$ & Ileum \\
\hline $\begin{array}{l}\text { Villous height, } \mu m \\
\text { Con }\end{array}$ & $442.1 \pm 19.4$ & $496.8 \pm 9.2$ & $405.9 \pm 58.0$ & $530.7 \pm 23.7$ \\
Exp & $558.7 \pm 40.7^{*}$ & $533.4 \pm 12.3^{*}$ & $597.9 \pm 73.0^{\#}$ & $549.8 \pm 21.1$ \\
& & & & \\
Crypt depth, $\mu m$ & $152.8 \pm 25.0$ & $176.6 \pm 8.1$ & $167.2 \pm 27.0$ & $184.1 \pm 13.6$ \\
$\quad$ Con & $211.7 \pm 12.1^{\#}$ & $202.7 \pm 4.1^{\#}$ & $230.5 \pm 24.9$ & $232.6 \pm 23.7$ \\
Exp & & & & \\
Villous height/crypt depth & & & & \\
$\quad$ Con & $2.89 \pm 0.41$ & $2.82 \pm 0.08$ & $2.46 \pm 0.09$ & $2.93 \pm 0.25$ \\
Exp & $2.63 \pm 0.08$ & $2.63 \pm 0.04$ & $2.58 \pm 0.04$ & $2.43 \pm 0.24$ \\
\hline
\end{tabular}

" compared with control $\mathrm{P}<0.05,{ }^{*} 0.05<\mathrm{P}<0.15$

Concentrations of mucosal DNA in duodenum and proximal jejunum (Table 2) are higher in Exp than that in Con goats $(\mathrm{P}<0.05)$. The RNA concentration did not differ between groups. Therefore, the ratio of RNA/DNA, compared with Con, 
was reduced in Exp of duodenum $(\mathrm{P}=0.10)$ and of proximal jejunum $(\mathrm{P}<0.05)$. The protein contents of Exp increased in duodenum $(\mathrm{P}=0.08)$ and in proximal jejunum $(\mathrm{P}=0.10)$, the $\gamma$-GT activity increased in duodenum $(\mathrm{P}<0.05)$ and proximal jejunum $(\mathrm{P}<0.05)$, the AP activity however, enhanced only in proximal jejunum $(\mathrm{P}=0.08)$ but not in other intestinal sections.

Cysteamine hydrochloride administration did not alter the mucosal morphology or mucosal compositions in distal jejunum or ileum. There were no differences between Exp and Con groups for villous height, crypt depth or concentrations of DNA, RNA or protein in distal jejunum or ileum. Neither $\gamma$-GT nor AP activities varied in both groups for distal jejunum or ileum.

Table 2. Influence of orally administrated cysteamine hydrochloride on small intestinal mucosa compositions in postoperative goats $(n=4)$

\begin{tabular}{|c|c|c|c|c|}
\hline & Duodenum & $\begin{array}{c}\text { Proximal } \\
\text { jejunum }\end{array}$ & $\begin{array}{c}\text { Distal } \\
\text { jejunum }\end{array}$ & Ileum \\
\hline \multicolumn{5}{|l|}{$D N A^{1}$} \\
\hline Con & $2.58 \pm 0.06$ & $2.44 \pm 0.04$ & $2.36 \pm 0.17$ & $2.43 \pm 0.16$ \\
\hline Exp & $2.92 \pm 0.05^{*}$ & $2.81 \pm 0.07^{*}$ & $2.48 \pm 0.08$ & $2.33 \pm 0.11$ \\
\hline \multicolumn{5}{|l|}{$R N A^{I}$} \\
\hline Con & $4.05 \pm 0.04$ & $4.14 \pm 0.04$ & $4.10 \pm 0.06$ & $4.19 \pm 0.13$ \\
\hline Exp & $4.33 \pm 0.05$ & $4.46 \pm 0.08$ & $4.15 \pm 0.04$ & $4.09 \pm 0.04$ \\
\hline \multicolumn{5}{|c|}{ Protein $^{1}$} \\
\hline Con & $118.8 \pm 7.3$ & $111.5 \pm 3.7$ & $113.1 \pm 6.7$ & $104.1 \pm 3.9$ \\
\hline Exp & $133.3 \pm 6.5^{\#}$ & $121.1 \pm 5.4^{\#}$ & $115.0 \pm 4.2$ & $109.5 \pm 2.5$ \\
\hline \multicolumn{5}{|c|}{$R N A / D N A$} \\
\hline Con & $1.58 \pm 0.05$ & $1.70 \pm 0.04$ & $1.77 \pm 0.13$ & $1.74 \pm 0.09$ \\
\hline Exp & $1.48 \pm 0.04^{\#}$ & $1.59 \pm 0.02^{*}$ & $1.68 \pm 0.06$ & $1.76 \pm 0.07$ \\
\hline \multicolumn{5}{|l|}{$\gamma-G T^{2}$} \\
\hline Con & $57.6 \pm 1.6$ & $48.8 \pm 1.6$ & $29.8 \pm 1.6$ & $24.7 \pm 1.9$ \\
\hline Exp & $76.6 \pm 4.9^{*}$ & $72.8 \pm 5.7^{*}$ & $28.5 \pm 2.4$ & $26.0 \pm 1.2$ \\
\hline \multicolumn{5}{|l|}{$A P^{2}$} \\
\hline Con & $71.3 \pm 15.5$ & $59.6 \pm 10.0$ & $38.5 \pm 3.7$ & $36.0 \pm 4.4$ \\
\hline Exp & $82.4 \pm 18.1$ & $74.8 \pm 13.5^{\#}$ & $40.6 \pm 3.3$ & $38.8 \pm 2.3$ \\
\hline
\end{tabular}

compared with control * $\mathrm{P}<0.05,{ }^{*} 0.05<\mathrm{P}<0.15,{ }^{1} \mathrm{mg} / \mathrm{g}$ mucosa, ${ }^{2} \mathrm{U} / \mathrm{g}$ mucosa

The isolated duodenal epithelial cells in primary culture responded to cysteamine hydrochloride positively (Table 3 ). Incorporation of ${ }^{3} \mathrm{H}-\mathrm{TdR}$ into DNA markedly increased $(\mathrm{P}<0.05)$ in Exp, indicated an increment of DNA synthesis of $\mathrm{S}$ phase in cell cycle. The T-AOC enhanced in cysteamine treated cells by $16 \%$ $(\mathrm{P}<0.05)$ and the GSH by $20 \%(\mathrm{P}<0.05)$. 
Table 3. Effect of oral cysteamine treatment on lymphocyte proliferation (SI) in postoperative goats and effects of cysteamine on DNA synthesis, total anti-oxidation capacity (T-AOC) and glutathione concentration $(\mathrm{GSH})$ of small intestinal cells of cows $(n=3)$ in primary culture

\begin{tabular}{lcccc}
\hline & $\begin{array}{c}\mathrm{SI}^{1} \\
\mathrm{n}=3\end{array}$ & $\begin{array}{c}\mathrm{DNA}^{1} \text { synthesis } \\
\text { DPM, }\end{array}$ \\
\hline Con & $12.68 \pm 1.56$ & $561 \pm 106$ & $\begin{array}{c}\mathrm{T}-\mathrm{AOC}^{2} \\
\mathrm{IU} / 10^{7} \text { cell }\end{array}$ & $\begin{array}{c}\mathrm{GSH}^{2} \\
\mathrm{IU} / 10^{7} \text { cell }\end{array}$ \\
Exp & $31.03 \pm 7.53^{*}$ & $3280 \pm 468^{* *}$ & $2.35 \pm 0.02$ & $424 \pm 21$ \\
\hline
\end{tabular}

compared with control ${ }^{*}-\mathrm{P}<0.05,{ }^{* *}-\mathrm{P}<0.01,{ }^{1}$ blood collected from jugular vein of goats orally treated with (Exp) or without cysteamine (Con) at day $14,{ }^{2}$ cells from mid-duodenum were isolated, incubated and treated with cysteamine $10 \mu \mathrm{g} / \mathrm{ml}$ (Exp) or $0 \mu \mathrm{g} / \mathrm{ml}$ (Con)

\section{DISCUSSION}

In current study the enlarged villous length in duodenum and proximal jejunum of Exp group suggest that cysteamine accelerates the renewal of mucosa. This postulate is supported by observations that duodenal and proximal jejunal RNA/DNA ration reduced in goats orally administered with cysteamine, and DNA synthesis increased in duodenal cells in primary cell culture treated with cysteamine. It is therefore concluded that hyperplasia rather than hypertrophy in this study is induced by cysteamine in intestinal mucosa, because the increased DNA synthesis in crypt cells (Potten, 1998) and the enlarged crypts depth occurred synchronously.

Previous study reported that glutamine increases intestinal villous height, stimulates gut mucosal cellular proliferation, and maintains mucosal integrity (Miller, 1999). The effectiveness of glutamine appears to be mediated via glutathione synthesis (Babu et al., 2001). In present study cysteamine treatment leads to a marked increment of intracellular glutathione synthesis, which is benefit to mucosal regeneration.

\section{CONCLUSIONS}

Oral cysteamine administration accelerated the regeneration of mucosa in terms of morphology, compositions and enzyme activities for duodenum and proximal jejunum with surgery trauma. These effects could be the result of enhanced antioxidant capacity and restoring the immune activity stimulated by cysteamine hydrochloride, in addition to its long been recognized effects of depletion of somatostatin and augment of growth hormone and IGF-1 concentrations on intestinal mucosa. 


\section{REFERENCES}

Babu R., Eaton S., Drake D.P., Spitz L.Y., Pierro A., 2001. Glutamine and glutathione counteract the inhibitory effects of mediators of sepsis in neonatal hepatocytes. J. Pediat. Surg. 36, 282-286

Beal M.F., Martin J.B., 1984. Depletion of striatal somatostatin by local cysteamine injection. Brain Res. 308, 319-324

Fink M.P., 1991. Gastrointestinal mucosal injury in experimental models of shock, trauma, and sepsis. Crit. Care Med. 19, 627-641

McLeod K.R., Harmon D.L., Schillo K.K., Mitchell G.E., 1995. Cysteamine-induced depletion of somatostatin in sheep: time course of depletion and changes in plasma metabolism, insulin, and growth hormone. J. Anim. Sci. 73, 77-87

Miller Al., 1999. Therapeutic considerations of L-glutamine: a review of the literature. Altern Med. Rev. 4, 239-248

Potten C.S., 1998. Stem cells in gastrointestinal epithelium: numbers, characteristics and death. Philos. Trans. R Soc. Lond. B Biol. Sci. 353, 821-830

Shen Z.M., Xie H.M., 2004. Cysteamine attenuates suppression of peripheral IL-2 and lymphocytic proliferation induced by ruminal and duodenal operations in goats. Acta Biol. Exp. Sinica 37, 501-506

Suzy A., Comhair A., Erzurum S.C., 2002. Antioxidant responses to oxidant-mediated lung diseases. Amer. J. Physiol. - Lung Cell M. Ph. 283, L246-L255

Yang X.J., Huang J.A., Lei W., Zhu Y.B., Zhang X.G., 2006. Antitumor effects of cocultured dendritic cells and cytokine-induced killer cells on lung cancer in vitro and in vivo. Ai Zheng $25,1329-1333$

Zitnan R., Kuhla S., Nurnberg K., Schoenhusen U., Ceresnakova Z., Sommer A., Baran M., Greserova G., Voigt J., 2003. Influence of the diet on the morphology of ruminal and intestinal mucosa and on intestinal carbohydrase levels in cattle. Vet. Med.-Czech. 48, 177-182 